Vol. 7, $n^{\circ} 1 \mid 2003$

Varia

\title{
Jean-Claude Farcy, L'histoire de la justice française de la Révolution à nos jours
}

Paris, PUF, coll. Droit et justice, 2001, 494 pp

\section{Guillaume Mouralis}

\section{OpenEdition}

\section{Journals}

Édition électronique

URL : https://journals.openedition.org/chs/634

DOI : 10.4000/chs.634

ISSN : $1663-4837$

\section{Éditeur}

Librairie Droz

Édition imprimée

Date de publication : 1 juillet 2003

Pagination : 150-152

ISBN : 2-600-00865-9

ISSN : 1422-0857

\section{Référence électronique}

Guillaume Mouralis, « Jean-Claude Farcy, L'histoire de la justice française de la Révolution à nos jours »,

Crime, Histoire \& Sociétés / Crime, History \& Societies [En ligne], Vol. 7, $n^{\circ} 1$ | 2003, mis en ligne le 24 février 2009, consulté le 23 mars 2022. URL : http://journals.openedition.org/chs/634 ; DOI : https:// doi.org/10.4000/chs.634

Ce document a été généré automatiquement le 23 mars 2022

(C) Droz 


\section{Jean-Claude Farcy, L'histoire de la justice française de la Révolution à nos jours}

Paris, PUF, coll. Droit et justice, 2001, 494 pp

Guillaume Mouralis

\section{RÉFÉRENCE}

Jean-Claude Farcy, L'histoire de la justice française de la Révolution à nos jours, Paris, PUF, coll. Droit et justice, 2001, $494 \mathrm{pp}$.

1 Jean-Claude Farcy dresse un bilan historiographique de "l'histoire de la justice française »- prise au sens large - «de la Révolution à nos jours ». Il s'agit d'un « panorama le plus complet possible» (16) des travaux réalisés entre 1970 et 1999, soit «près de 5200 références (...) dont beaucoup (...) émanent d'érudits locaux ou de professionnels de la justice » (17).

2 Après un premier chapitre s'interrogeant sur la jeunesse relative de l'objet d'étude, cet ouvrage entend explorer " les quatre grandes directions empruntées par la recherche " (18) depuis une trentaine d'années (quatre chapitres suivants).

3 Les causes de la jeunesse de l'histoire de la justice sont autant internes à la discipline qu'externes à celle-ci. Les grands "paradigmes» des années 1960 et 1970 (structuralisme, longue durée, histoire sérielle...) auraient, d'après l'auteur, contribué à confiner cette histoire aux marges de la recherche. Il nous semble que l'explication est à nuancer, car dans un sens ces perspectives dominantes n'auraient pas dû exclure $a$ priori les objets judiciaires et/ou juridiques, si l'on songe par exemple à l'importance souvent négligée aujourd'hui de la moyenne et longue durée des catégorisations ou des habitus juridiques. Une cause plus pertinente nous paraît avoir été le désintérêt général pour le "phénomène étatique ", dont on n'apercevait pas suffisamment, du moins en histoire, le rôle d'encadrement ou même de façonnage du social à travers par exemple 
son pouvoir de classement au moyen de normes plus ou moins contraignantes. Quant aux causes externes à la discipline, elles nous semblent plus convaincantes : il s'agit de la montée en puissance depuis une vingtaine d'années au moins des modes juridiques de règlements des conflits (augmentation considérable du contentieux) et du pouvoir judiciaire au sens large.

4 La criminalité et ses lectures (61-148) constituent la première de ces directions et sans doute une des plus anciennes. On retiendra ici avant tout l'effort fait par l'auteur pour distinguer entre les grandes approches de l'histoire de la criminalité et pour proposer des pistes nouvelles de recherche (100-148). Parmi les grandes approches (histoire des représentations, étiologie du crime, approche anthropologique), une des plus heuristiques semble finalement être l'approche sociologique, qui à la suite de Durkheim, s'interroge sur la construction à la fois pénale et sociale de la criminalité. Le "détour " par les théories du crime, en particulier par une sociologie criminelle qui entend explorer « la réaction sociale à la transgression des règles ", permet d'orienter la recherche vers une approche de type interactionniste, à condition toutefois de ne pas faire l'impasse d'une étude des transgressions elles-mêmes.

5 «Normes, institutions et pratiques judiciaires » constituent la seconde thématique explorée par la recherche des trois dernières décennies (149-264). Comme le souligne l'auteur, les historiens des lettres ne se sont qu'incidemment penchés sur la question des modes de production du droit, en particulier le droit pénal. Malgré tout, trois types d'acteurs ont retenu l'attention: les " entrepreneurs de morale ", les acteurs politiques (gouvernement, parlement) et les mouvements d'opinion. Le rôle de la jurisprudence comme de la doctrine dans les processus de production et de (re)définition des normes restent souvent dans l'ombre. Malgré un intérêt ancien pour les institutions judiciaires, la plupart des études sur ce thème portent encore sur le moment fondateur de l'appareil judicaire moderne, c'est-à-dire la Révolution et l'Empire. Les travaux en général plus récents consacrés au personnel judiciaire (magistrats et avocats avant tout) restent également attachés à la période révolutionnaire et sont, là aussi, marqués par des préoccupations actuelles. Quant aux pratiques judiciaires, on note un intérêt pour l'attitude des justiciables, que ce soit à travers la question de l'infrajudiciaire (soit les formes d'évitememt de la justice pénale) ou, au contraire, celle de la litigiosité (au civil).

6 Un troisième courant porte son attention sur les " prisons et [les] pénalités » (265-334). Ces études ont d'abord fleuri à partir de la fin des années 1960, dans le sillage d'un intérêt pour les marginaux et d'interrogations sur «l'impossible prison ». Les travaux sur le régime des peines et l'évolution des conceptions pénales ont été renouvelés par deux grandes interprétations générales : celle de Michel Foucault (Surveiller et punir) et celle de Georg Rusche et Otto Kirschheimer (Peine et structure sociale) qui envisagent la prison comme mode de domination et de régulation sociale. En partie marqués par ces modèles, les historiens se sont surtout penchés sur les diverses formes de l'enfermement (prison et bagne en particulier) et sur la pratique de la peine de mort depuis la Révolution.

7 La recherche historique des dernières décennies s'est enfin abondamment consacrée au rôle de la justice dans les répressions politiques (335-452). J.-C. Farcy pose certes la question épineuse de savoir s'il existe une "spécificité de la justice politique». Toutefois, à la différence des chapitres précédents, il ne revient pas sur les grandes interprétations théoriques du phénomène en question, en particulier sur l'ouvrage 
classique de Otto Kirschheimer (Political Justice. The Use of Legal Procedure for Political Ends, 1961), qui souligne les contradictions essentielles de la justice politique, «fatalité et promesse » illusoire pour les victimes, efficacité limitée pour le pouvoir. Mais on pourrait renvoyer également aux analyses de Hanna Arendt (sur le rôle de la justice dans les systèmes totalitaires) ou d'Annie Kriegel (Les grands procès dans les systèmes communistes), il est vrai menées dans d'autres contextes que le contexte français. Après avoir noté l'intérêt récent (en France) pour la violence politique et le flou propre aux infractions politiques, l'auteur souligne que cette justice se caractérise par le recours à des juridictions d'exception, à des pénalités souvent particulières et, pourrait-on ajouter, à des magistrats soigneusement choisis et parfois non professionnels. Toutefois, comme le montre bien l'auteur, la tentation a toujours été grande de recourir aux juridictions et au droit pénal ordinaires afin de dénier tout caractère politique à des opposants ravalés ainsi au rang de simples délinquants. Après un aperçu chronologique de «la litanie des répressions politiques » de la Révolution à la guerre d'Algérie (362-423), l'ouvrage s'interroge sur la notion de crime d'État, qui recouvre bien souvent des pratiques extrajudiciaires. On regrettera ici l'absence de références aux analyses menées à l'étranger sur la criminalité dite "systémique » et la difficulté pour la justice d'un État démocratique de punir a posteriori de tels crimes au moyen du droit pénal... ordinaire. Il est également frappant que l'historiographie française semble largement ignorer les réflexions menées en Allemagne et dans les pays anglo-saxons sur le rôle de la justice pénale dans l'économie générale de la gestion étatique d'un passé dictatorial (à côté d'autres mesures telles que l'épuration professionnelle ou les réparations en faveur des victimes).

En somme, cet ouvrage nous paraît être un outil indispensable à tous ceux notamment les historiens - qui travaillent sur des phénomènes judiciaires. Il leur offre en effet la possibilité de mettre en perspective leur propre travail par rapport aux grands courants historiographiques de ce champ relativement nouveau.

\section{AUTEURS}

\section{GUILLAUME MOURALIS}

IHTP, Cachan / Centre Marc Bloch, Berlin, g.mouralis@free.fr 